\title{
LAS MÁXIMAS DE LA EXPERIENCIA EN LA JURISPRUDENCIA MEXICANA
}

\author{
MAXIMS OF EXPERIENCE \\ in Mexican Case Law
}

\section{AS MÁXIMAS DA EXPERIÊNCIA NA JURISPRUDÊNCIA MEXICANA}

HÉCTOR MANUEL GUZMÁN RUÍZ*

* https://orcid.org/0000-0003-2086-7069. Universidad Panamericana, México. hguzman@up.edu.mx

RECIBIDO: 11/O3/2019. ENVÍO A PARES: 19/03/2019 APROBADO POR PARES: 10/O4/2019. ACEPTADO: 16/O6/2019

DOI: $10.5294 / D I K A .2019 .28 .2 .6$

PARA CITAR ESTE ARTÍCULO / TO REFERENCE THIS ARTICLE / PARA CITAR ESTE ARTIGO HÉCTOR MANUEL GUZMÁN RUíz, “LAS MÁXIMAS DE LA EXPERIENCIA EN LA JURISPRUDENCIA MEXICANA”, EN DÍKAION 28, 2 (2019), 355-384. 


\section{RESUMEN}

El texto analiza un corpus de tesis jurisprudenciales generadas por los Tribunales de Amparo mexicanos, en los que se advierten distintas funciones en el uso del concepto "máximas de la experiencia", para lo cual utiliza dos criterios de clasificación: 1) como concepto autónomo: para valoración probatoria, para colmar lagunas normativas, inferir conclusiones fácticas, generar un parámetro objetivo de verdad, sustentar una decisión razonable, y 2) en la correlación con otros conceptos de valoración probatoria del tipo: método científico, reglas de la lógica, pensar reflexivo, sana crítica, prueba libre, sentido común. De ello se concluye que la jurisprudencia mexicana trata a las "máximas de la experiencia" como un tópico de lugar común, tanto desde el punto de vista lingüístico como epistemológico.

\section{PALABRAs Clave}

Máximas de la experiencia; jurisprudencia; juicio de amparo; valoración de pruebas; tópica. 


\section{ABSTRACT}

This paper analyzes a corpus of case-law theses produced by the Mexican Courts of Amparo in which different functions of the concept "maxims of experience" are noted. Two classification criteria are used: 1) As an autonomous concept: To weigh evidence, bridge regulatory gaps, infer factual conclusions, set an objective parameter of truth, and support a reasonable decision; and 2) In correlation with other concepts of weighing of evidence: Scientific method, rules of logic, reflective thinking, healthy criticism, free testing, and common sense. In interpreting the findings, it is concluded that Mexican case law deals with the "maxims of experience" as a common place, both from the linguistic and epistemological points of view.

\section{KEYWORDS}

Maxims of experience; case law; amparo trial; weighing of evidence; topic. 


\section{RESUMO}

Este texto analisa um corpus de teses jurisprudenciais geradas pelos Tribunais de Amparo mexicanos, nos quais são advertidas diferentes funções no uso do conceito "máximas da experiência"; para isso, utiliza dois critérios de classificação. O primeiro como conceito autônomo: para valoração da prova, para preencher lacunas regulatórias, para inferir conclusões fáticas, para gerar um parâmetro objetivo de verdade e para justificar uma decisão razoável. O segundo se refere à correlação com outros conceitos de valoração da prova do tipo: método científico, regras da lógica, pensar reflexivo, livre convencimento do juiz, prova livre, senso comum. Disso, conclui-se que a jurisprudência mexicana trata as "máximas da experiência" como um tópico de lugar comum, tanto do ponto de vista linguístico quanto epistemológico.

\section{PALAVRAS-CHAVE}

Máximas da experiência; jurisprudência; julgamento de amparo; valoração de prova; tópica. 
SUMARIO: INTRODUCCIÓN. 1. BREVE CARACTERIZACIÓN DE LA JURISPRUDENCIA EN MÉXICO. 2. CORPUS JURISPRUDENCIAL DE TRABAJO. 3. MÁXIMAS DE LA EXPERIENCIA Y VALORACIÓN PROBATORIA. 4. MÁXIMAS DE LA EXPERIENCIA Y CORRELACIONES CON OTROS CONCEPTOS DE VALORACIÓN PROBATORIA. 5. INTERPRETACIÓN DE HALLAZGOS: INSUMOS INTELECTUALES FRENTE A INSUMOS PRÁCTICOS PARA LA DECISIÓN PRUDENCIAL DE CASOS CONCRETOS. 6. CONCLUSIONES. BIBLIOGRAFÍA.

\section{INTRODUCCIÓN}

La versión electrónica del Semanario Judicial de la Federación (SJF), disponible en la página institucional de la Suprema Corte de Justicia de la Nación (SCJN) ${ }^{1}$ de México, suele utilizarse como motor de búsqueda por jueces y litigantes para consultar el criterio judicial pertinente a fin de resolver un caso concreto, pero también puede servir como instrumento para visibilizar la actuación de los juzgadores federales mexicanos desde un punto de vista técnico a la vez que más amplio, y para apreciar las transversalidades en sus razonamientos (en sus continuidades y discontinuidades) capitalizando, para estos propósitos, una gran diferencia entre la tecnologia de la palabra escrita y la digital: la posibilidad de agilizar la identificación de los precedentes, de agruparlos y sistematizarlos para advertir recurrencias en distintas posibilidades de uso (en lo sucesivo, "regularidades de uso") sobre cómo se entiende un determinado concepto normativo, cómo se aplica una misma institución procesal, cómo se valora una prueba, etcétera. Algo así se pretende en este documento: sistematizar los resultados de la indagación, no para buscar respuestas para un caso particular, sino para identificar esquemas argumentativos utilizados por los jueces de amparo subyacentes a esas decisiones concretas y, así, abonar a la mejor comprensión del razonamiento judicial.

Con ello, se busca contribuir a una labor académica enfocada, antes que en entrecruzar posicionamientos doctrinarios sobre la forma en que razonan los jueces o realizar deducciones autoevidentes basadas en intuiciones o en ejemplos nítidos, pero aislados, en acudir a la fuente directa para obtener insumos empíricos (antes que teóricos) transversales y, por tanto, representativos para abonar ese tipo de discusiones. De manera que las construcciones académicas sobre la decisión judicial (en el campo de la argumentación jurídica, por ejemplo) no dependan solamente de las interpretaciones de un observador externo o de las implicaciones, más o menos anecdóticas, del comentario de sentencias representativas.

Con esta perspectiva, a continuación se intenta una aproximación a las tesis de jurisprudencia mexicanas, en la que se explora el concepto de "máximas de la experiencia" (ME) -cuyo motivo de elección se explica más adelante- a partir de los resultados del motor de búsqueda del SJF para esta voz de entre las decenas de miles de criterios jurisprudenciales generados por los Tribunales de Amparo (TrAm) y, en el último apartado, se emiten algunas líneas interpretativas a modo

1 https://sjf.scjn.gob.mx/sjfsist/Paginas/tesis.aspx 
de conclusiones preliminares sobre los hallazgos empíricos detectados, que pudieran detonar trabajos posteriores.

Como objetivo general del análisis, lo que se busca con este ejercicio es detectar los usos que los TrAm dan a las ME en las tesis jurisprudenciales; o sea, advertir para qué estos órganos generan un criterio en el que se valen de este concepto, y de ahí establecer posibles implicaciones con la prudencia judicial ${ }^{2}$ que rige el sentido de la decisión a las circunstancias particulares de cada caso concreto y, como objetivos específicos, identificar dos posibilidades de uso en concreto que, en consecuencia, se corresponden con los dos criterios de clasificación para las tesis en cuestión:

- La utilización de las ME para la valoración probatoria (a fin de apreciar cada prueba, para colmar lagunas legislativas, entre otros).

- Respecto a cómo los TrAm asocian las ME con otros conceptos igualmente pertinentes para valorar las pruebas (los principios de la lógica, los conocimientos científicos, el sentido común, etcétera).

Tres ideas antes de cerrar esta introducción.

Primera, como se hará evidente hacia el final de este texto, la conceptualización de las ME es, por decir lo menos, escurridiza, lo que amerita un trabajo que se enfoque, en exclusiva, en tratar de dilucidar sus contornos de la manera más precisa posible; por lo que aquí se refieren un par de definiciones enteramente provisionales para efectos de este texto, solo en aras de facilitar al lector una imagen mental a la que asociar un concepto que será multirreferido. En ese tenor, la finalidad de las ME es "posibilitar el uso de conocimientos que surgen a partir de las vivencias de quienes pertenecen a la misma cultura. Es decir, a partir de cómo los miembros de una comunidad interpretan ciertos acontecimientos de la vida social"3, mientras que:

Una de las funciones que dichas máximas de la experiencia cumplen en el proceso, y que nos interesa destacar en este momento, es la de su utilización por el órgano jurisdiccional como instrumentos para la valoración de las pruebas. No se trata de

2 Siguiendo a Rodolfo Luis Vigo: "Es indudable que el juez precisamente por el carácter práctico de su razonamiento decisorio, normalmente debe optar entre diversos silogismos que solo puede apreciar apropiadamente si los tiene integramente construidos a su disposición; en terminologia clásica podriamos decir que la prudencia judicial antes de imperar o decidir tiene que conocer y juzgar entre diferentes alternativas que solo puede apreciar su las presenta no solo en las conclusiones, sino también con las premisas que las posibilitan" (Rodolfo Luis Vigo, "Razonamiento justificatorio judicial", en Doxa 21 (1998), p. 495). Igualmente: "La objetividad del juicio prudencial depende en primer lugar del adecuado análisis del caso, es decir, de un análisis que comience por distinguir entre las circunstancias relevantes y la que son irrelevantes, y luego considere todas las que son relevantes. La falta de atención a las circunstancias conduce a juicios erróneos" (Jorge ADAME, "El derecho como jurisprudencia”, en Ars Iuris 12 (1994), p. 26).

3 Rodrigo Coloma y Claudio SAn JuAn, "Lógica, ciencia y experiencia en la valoración de la prueba”, en Revista Chilena de Derecho 2 (2014), p. 678. 
que la máxima o regla de la experiencia sea utilizada como fuente de convicción por el juez sino que, existiendo prueba, se utiliza a los fines de su valoración. ${ }^{4}$

Segunda, este ayuno de certezas, no obstante, no incide en los criterios de clasificación que se intentan más adelante, como tampoco el que haya tesis que definan las $\mathrm{ME}^{5}$ y otras que no, en tanto que, sin negar que el TrAm pudiera tener como finalidad esa labor de explicitación conceptual (en sí mismo, también un tema digno de tratamiento específico), este es un trabajo con pretensiones eminentemente descriptivas, se agota con suministrar información empírica para discusiones posteriores (al igual que las reflexiones finales a partir de los hallazgos detectados): son las coincidencias -de base textual- que se advierten en las tesis de jurisprudencia que versan sobre las $\mathrm{ME}$ las que dan lugar a las clasificaciones (que en este texto se han denominado regularidades de uso) y no al revés.

Tercera, como se muestra a continuación, la jurisprudencia objeto de estas reflexiones tiene la mixtura de fuente del derecho (en tanto que lo decido por los TrAm interpreta el ordenamiento jurídico, interpretaciones que, en tanto son obligatorias para los demás tribunales, se constituyen a su vez en una especie de normas jurídicas individualizadas) y de su dimensión práctica en él, como articuladora del sistema jurídico mexicano; es este último aspecto el que aquí se privilegia ya que el enfoque de análisis no está orientado a desentrañar su sentido o el modo como engranan en la arquitectura normativa, sino a reflexionar sobre posibles esquemas de pensamiento con que los TrAm generan este tipo de discurso como parte de su función judicial y las posibles razones de ello.

\section{BREVE CARACTERIZACIÓN DE LA JURISPRUDENCIA EN MÉXICO}

Cabe destacar que la legislación mexicana utiliza de manera equívoca el término jurisprudencia, pues además de las connotaciones de fuente del derecho y de resultado de la actividad jurisdiccional, en ella convergen otros conceptos relevantes para identificar la labor jurisdiccional, como lo es el precedente (los casos concretos que, con ciertas características y por parte de determinados órganos jurisdiccionales, dan lugar a la jurisprudencia), criterio jurisprudencial (la ratio o consideración interpretativa sobre lo dispuesto por una norma de cualquier rango emitida por dichos órganos jurisdiccionales cualificados) que puede ser aislado (si no cumple los requisitos para ser obligatorio para los juzgadores de menor rango $\mathrm{y}$, por tanto, solo es orientador) o vinculante (cuando el criterio, en efecto, constituye jurisprudencia y es, en consecuencia, mandatorio para los demás órganos

4 Emiliano Sandoval Delgado, "La libre valoración de la prueba en los juicios orales: su significado actual”, en Letras Juridicas 13, (2011), p. 14.

5 Por ejemplo, las ME "son las reglas de vida o verdades de sentido común que contribuyen de un modo eficaz a la formación de la presunción judicial". "Prueba presuncional humana. Su valoración (Código de Comercio). Novena Época, Tribunales Colegiados de Circuito, jurisprudencia, materia civil, tesis: I.4o.C. J/25. 
jurisdiccionales), así como el de tesis jurisprudencial (el formato y la redacción en las que se expresa el criterio jurisprudencial). ${ }^{6}$

En esos términos, también debe tenerse presente que si una institución procesal ha distinguido al sistema jurídico mexicano es el juicio de amparo que, por lo demás, no sería aventurado decir que ha delineado e incide de manera determinante en la marcha y las posibilidades del sistema completo (para bien y para mal), ${ }^{7}$ en tanto que ya sea en su vía directa o indirecta, prácticamente cualquier acto de autoridad que agravie a un particular es susceptible de ser conocido por los juzgadores federales ${ }^{8}$ incluidas las determinaciones de otros órganos judiciales, lo que se traduce, en los hechos, en la preponderancia para la función jurisdiccional ordinaria (federal y local) de los criterios jurisprudenciales que son el resultado de la competencia ejercida por los TrAm e, indirectamente, para el conjunto de los operadores jurídicos (de los ámbitos Ejecutivo y Legislativo) que deben tomar en cuenta esos criterios aun cuando no les resultan vinculantes ya que, eventualmente, sus actos de autoridad estarán sujetos al control judicial para el que la jurisprudencia sí es vinculante.

6 Para un análisis a profundidad sobre la jurisprudencia de amparo en México, véase: Alejandro Sosa Ortiz, La jurisprudencia en la nueva Ley de Amparo, México, Porrúa, 2015.

$7 \quad$ "El juicio de amparo es el medio de defensa más importante que tiene el gobernado para combatir los actos autoritarios del poder público; sin embargo, en los últimos años se ha visto como un mecanismo en extremo formal y cerrado que dificulta en ciertos casos hacer efectivos los derechos y, en otros, los abusos del propio gobernado, distorsionando la esencia de este medio de defensa constitucional" (Vicente Fernández y Nitza SAMANiEgo, "El juicio de amparo: historia y futuro de la protección constitucional en México", en Revista IUS 27 (2011), pp. 199-200). "Si este procedimiento nacional padece de vicios y hasta deformidades, no ha sido culpa de la institución misma; en cambio, ha salvado muchas vidas, protegido muchas libertades defendido muchos patrimonios y logrado, algunas veces, mantener al poder dentro del limite de sus atribuciones" (Jorge F. Gaxiola, "El juicio de amparo", en Mariano Otero, visionario de la República. A 200 años de su nacimiento, Vol. A, México, Suprema Corte de Justicia de la Nación-El Colegio de Jalisco, p. 208). Para profundizar en la importancia del juicio de amparo en el sistema mexicano, su naturaleza e implicaciones, véase: Suprema Corte de Justicia de lA NACión, Elementos para el estudio del Juicio de Amparo, México, SCJN, 2017; Los principios fundamentales del juicio de Amparo, SCJN, 2016; Raymundo GiL, El Amparo y los derechos humanos, México, Ubijus, 2017; Luciano Silva, El control de la constitucionalidad y el juicio de Amparo en México, México, Porrúa, 2017; Vicente Roberto Arenal Martínez, La técnica en el juicio de Amparo, México, Flores Editor, 2016; Eduardo Ferrer MAC-GREGor, El nuevo juicio de Amparo: guía de la reforma constitucional y la nueva ley de Amparo, México, Porrúa, 2016; El juicio de Amparo y el sistema procesal penal acusatorio, México, SegobSetec, 2012; Francisco A. Lembo Rosales, El nuevo régimen constitucional del juicio de Amparo y los derechos humanos: a la luz de la reforma constitucional del 2011 y con base en la nueva Ley de Amparo, México, Flores Editor, 2016; Wendy Mercedes JARguí, La naturaleza subjetiva del Amparo: análisis histórico-comparado y de derecho español, México, Porrúa, 2016; Rodolfo Monargue, La suspensión en el juicio de Amparo: planteamiento esquemático, México, Porrúa, 2016; Germán Eduardo Baltazar, Derechos humanos, derechos fundamentales, juicio de Amparo y reparación integral: derechos humanos reconocidos en la Constitución Mexicana y su justiciabilidad mediante el juicio de Amparo, México, Complejo Educativo de Desarrollo Integral, 2015; José Vicente TroColli, Evolución del juicio de Amparo como medio de control constitucional, México, Porrúa, 2013; Héctor FIX ZAMUdio, Las reformas en derechos humanos, procesos colectivos y Amparo como nuevo paradigma constitucional, México, UNAM-IIJ, 2012.

8 Como se advierte de la amplitud, sin matices, de la fracción I del artículo 1 de la Ley de Amparo, Reglamentaria de los artículos 103 y 107 de la Constitución Política de los Estados Unidos Mexicanos (LA), que establece como objeto de este juicio "resolver toda controversia" por: "Normas generales, actos u omisiones de autoridad que violen los derechos humanos y las garantías otorgadas para su protección por la Constitución Política de los Estados Unidos Mexicanos, así como por los tratados internacionales de los que el Estado Mexicano sea parte". 
A lo anterior debe agregarse la forma en que históricamente se ejerció en México la interpretación constitucional a partir de un control concentrado fuerte, que dio exclusividad a los TrAm para realizar interpretaciones del texto constitucional. ${ }^{9}$

Así, un primer rasgo que podemos destacar de la jurisprudencia mexicana para fines de este trabajo consiste en el rol disciplinario que ejerce sobre el conjunto de los discursos judiciales deliberativos (las consideraciones de la sentencia), en un esquema de círculos concéntricos que tiene en su núcleo a los criterios generados por el Pleno de la SCJN, luego las Salas de la misma, siguiendo con los Plenos de Circuito y los Tribunales Colegiados de Circuito, en términos de los efectos vinculantes que se desprenden del artículo 217 de la Ley de Amparo (LA). ${ }^{10}$

A ello se vincula un segundo rasgo, relativo a la propia positivización de la jurisprudencia en LA, que puede verse como una especie de extensión-complemento de las posibilidades normativas de la legislación para regir la conducta de los operadores jurídicos en general y, específicamente, de los órganos jurisdiccionales, para la salvaguarda de la seguridad jurídica en clave positivista: i) desde la jurisprudencia y ii) en la jurisprudencia.

La seguridad jurídica desde la jurisprudencia comprende el ámbito de las interpretaciones jurisdiccionales posibles, en un ejercicio que no solo conlleva la resolución del problema jurídico mediante la ordinaria tarea de interpretación normativa, sino la fijación, con pretensiones de exactitud, del significado atribuible a cualquier norma o de las implicaciones constitucionales de cualquier acto de autoridad que vía amparo caiga en el conocimiento de los tribunales federales,

9 Esquema que solo de manera reciente se ha atemperado para dar lugar a la coexistencia de un control constitucional y convencional difuso del que también participa el resto de los tribunales para evaluar si una ley $\mathrm{u}$ acto son contrarios a los catálogos de derechos constitucionales y convencionales, ello como consecuencia del cumplimiento dado por la SCJN a la condena al Estado mexicano por parte de la Corte Interamericana de Derechos Humanos en el célebre caso Radilla Pacheco, que no pocos consideran que ha marcado un antes y un después en la historia constitucional mexicana: "por representar el primer fallo internacional donde existe una obligación precisa hacia los jueces mexicanos para aplicar no solo los derechos humanos previstos en el Pacto de San José, sino, ahora, la jurisprudencia convencional de la Corte IDH, lo que implica que nuestros jueces deben interpretar la Constitución a la luz de la CADH y de la jurisprudencia de ese tribunal internacional” (Eduardo FERRER MAC-GREGOR y Fernando SILVA, "El caso Radilla y su impacto en el orden jurídico nacional”, en Jorge CARPIZo y César Astudillo (coords.), Constitucionalismo: dos siglos de su nacimiento en América Latina, México, UNAM-IIJ, 2013, p. 233).

10 "Artículo 217. La jurisprudencia que establezca la Suprema Corte de Justicia de la Nación, funcionando en pleno o en salas, es obligatoria para estas tratándose de la que decrete el pleno, y además para los Plenos de Circuito, los tribunales colegiados y unitarios de circuito, los juzgados de distrito, tribunales militares y judiciales del orden común de los Estados y del Distrito Federal, y tribunales administrativos y del trabajo, locales o federales.

La jurisprudencia que establezcan los Plenos de Circuito es obligatoria para los tribunales colegiados y unitarios de circuito, los juzgados de distrito, tribunales militares y judiciales del orden común de las entidades federativas y tribunales administrativos y del trabajo, locales o federales que se ubiquen dentro del circuito correspondiente.

La jurisprudencia que establezcan los tribunales colegiados de circuito es obligatoria para los órganos mencionados en el párrafo anterior, con excepción de los Plenos de Circuito y de los demás tribunales colegiados de circuito.

La jurisprudencia en ningún caso tendrá efecto retroactivo en perjuicio de persona alguna”. 
respecto de cualquier ordenamiento jurídico, municipal, estatal o federal, de cualquier materia y de cualquier figura sustantiva o procesal. ${ }^{11}$

La seguridad jurídica en la jurisprudencia comprende dos aspectos. El primero versa sobre la explicitación de los supuestos que dan lugar a su conformación (por reiteración de criterios, por contradicción y por sustitución), ${ }^{12}$ a cuándo cesan sus efectos ${ }^{13} \mathrm{y}$, en particular, a la nítida distinción entre precedente y jurisprudencia, a partir de la explicitación de los requisitos para que un fallo pueda integrar jurisprudencia, con lo cual se evita el tipo de problemas que TARUFFO ejemplifica en el sistema italiano. ${ }^{14}$

El segundo aspecto se refiere a la información que deben contener las tesis de jurisprudencia, igualmente delineada normativamente, en este caso en el artículo 218 de la LA ${ }^{15}$ (fracciones I a V del numeral en cuestión), cuya elaboración de-

11 Como muestran los rubros de las siguientes tesis, tomadas al azar en el motor de búsqueda: "Actualización al plan de desarrollo urbano sostenible para el centro de población del municipio de Juárez, Chihuahua 2016 (PDUS). Es inconstitucional, al no haberse publicado en el periódico oficial de la entidad el documento que la contiene". Décima Época, Tribunales Colegiados de Circuito, tesis aislada, materia constitucional, tesis XVII.2o.2 A (10a), registro: 2018112. "Recibo o factura de pago expedida por la comisión estatal de servicios públicos del estado de Baja California. Tiene el carácter de un crédito fiscal que no constituye una resolución definitiva para la procedencia del juicio administrativo estatal”. Décima Época, Plenos de Circuito, tesis de Jurisprudencia, materia administrativa, tesis: PC.XV. J/33 A (10a.), registro: 2017704. "Sucesión de derechos agrarios. Basta que la lista elaborada por el ejidatario sea ratificada ante notario en cuanto a contenido y firma para tenerla por formalizada ante fedatario público (art. 17 de la ley agraria)”. Novena Época, Segunda Sala, tesis de Jurisprudencia, materia administrativa, tesis 2a./J. 43/2011, registro: 162460.

12 "Artículo 215. La jurisprudencia se establece por reiteración de criterios, por contradicción de tesis y por sustitución”.

13 "Interrupción de la Jurisprudencia. Artículo 228. La jurisprudencia se interrumpe y deja de tener carácter obligatorio cuando se pronuncie sentencia en contrario. En estos casos, en la ejecutoria respectiva deberán expresarse las razones en que se apoye la interrupción, las que se referirán a las consideraciones que se tuvieron para establecer la jurisprudencia relativa.

Artículo 229. Interrumpida la jurisprudencia, para integrar la nueva se observarán las mismas reglas establecidas para su formación".

14 "El hecho es que en los sistemas que tradicional y tipicamente se fundamentan en el precedente, generalmente la decisión que se asume como precedente es una sola; mas aún, pocas decisiones sucesivas son citadas para sostener el precedente. De este modo, es fácil identificar cual decisión verdaderamente 'hace precedente'. En cambio, en sistemas como el italiano, en los que se alude a la jurisprudencia, se hace referencia generalmente a muchas decisiones. Algunas veces son docenas, o inclusive centenas, no obstante que no todas vengan citadas expresamente. Esto tiene varias implicaciones, entre las cuales está la dificultad, a menudo difícilmente superable, de establecer cuál debe ser la decisión verdaderamente relevante (si existe alguna), o bien de decidir cuántas decisiones se requieren para poder afirmar que existe una jurisprudencia relativa a una determinada interpretación de una norma" (Michele TARUFFo, "Precedente y jurisprudencia", en Precedente. Revista Jurídica (2007), pp. 87-88.

15 Artículo 218. Cuando la Suprema Corte de Justicia de la Nación, los Plenos de Circuito o los tribunales colegiados de circuito establezcan un criterio relevante, se elaborará la tesis respectiva, la cual deberá contener:

I. El título que identifique el tema que se trata;

II. El subtítulo que señale sintéticamente el criterio que se sustenta;

III. Las consideraciones interpretativas mediante las cuales el órgano jurisdiccional haya establecido el criterio;

IV. Cuando el criterio se refiera a la interpretación de una norma, la identificación de esta; y V. Los datos de identificación del asunto, el número de tesis, el órgano jurisdiccional que la dictó y las votaciones emitidas al aprobar el asunto y, en su caso, en relación con el criterio sustentado en la tesis. 
pende de que se establezca un "criterio relevante" (que al no explicitarse cuándo se actualiza esa condición, se entiende que queda a consideración del respectivo órgano judicial).

Del contenido del numeral en comentario debe llamar especialmente la atención la exigencia de que se explicite la información que deben contener los criterios: título-tema, subtítulo-sintesis del criterio y consideraciones-criterio, sin que a la par deba incluirse referencia alguna a las particularidades del caso (la cuestión planteada, los argumentos de las partes y, menos aún, de los hechos que dieron lugar a la litis), con lo cual, la tesis de jurisprudencia, escindida de casuística, es una especie de ratio decidendi en estado puro.

Detrás de esta directriz normativa podemos advertir el tipo de pretensiones de la ley positiva: que el criterio jurisprudencial adquiera el mayor grado de abstracción, de "aplicabilidad" - a lo que se abona que el texto de la tesis se formule de manera sintética, con lo que, al ayunar en detalles, se amplia su rango hipotético- y así, lo que en el caso particular fue componente conclusivo del ejercicio justificativo del tribunal, en el siguiente servirá de base para orientar (cuando no para obviar) la argumentación de la sentencia: cuando haya jurisprudencia aplicable al caso no es necesario mayor estudio, basta con invocarla para resolver el fondo; cuando sea solo un criterio aislado basta ceñir las consideraciones de la sentencia para arribar a la misma conclusión.

De esta manera, podemos entender que la jurisprudencia se encuentra en relación complementaria con la ley, no solo en cuanto a que modula el rango de sus aplicaciones, sino porque, igualmente, instrumenta sus pretensiones de aplicación omnicomprensiva.

Con este diseño legislativo surge la interrogante de si a pesar de ser la resolución judicial un ejercicio siempre apegado a las particularidades del caso, ¿cómo es que se da la operación de "empatar" el contenido de las tesis de jurisprudencia sin saber los pormenores del o los casos de los que esta ha derivado?

En ese tenor, ¿tiene la tesis de jurisprudencia la connotación de referir una regla de derecho, en tanto que se impone un mandato de todo o nada a los tribunales para su observancia? O antes bien, ¿puede funcionar como un principio y evidencia de esa posibilidad que sea el juzgador quien determine, a su arbitrio, si la tesis es aplicable o no, justo sobre la base de considerar las particularidades del caso que tiene que resolver a partir de la tesis en cuestión?

Además de los elementos señalados en las fracciones I, II, III y IV de este artículo, la jurisprudencia emitida por contradicción o sustitución deberá contener, según sea el caso, los datos de identificación de las tesis que contiendan en la contradicción o de la tesis que resulte sustituida, el órgano que las emitió, así como la votación emitida durante las sesiones en que tales contradicciones o sustituciones se resuelvan. 
Cualquiera que pudieran ser las respuestas, parecería que las opciones pasan por un tamiz de prudencia judicial en tanto que la aplicación de la tesis conlleva un ejercicio de apreciación del juez acerca de su elevado nivel de abstracción (se le entienda como regla o principio o algo más) respecto de las particularidades de cada caso; de ahí que ante este escenario cobre relevancia dilucidar si está en las posibilidades mismas de las tesis de jurisprudencia contribuir a ese ejercicio de prudencia judicial y cómo es que pueden hacerlo. ${ }^{16}$

\section{CORPUS JURISPRUDENCIAL DE TRABAJO}

En aras de avanzar en la dirección planteada, en las líneas por seguir se acomete un análisis respecto de las posibilidades de las tesis de jurisprudencia para orientar la prudencia judicial.

Para ello, a partir de la búsqueda en el SJF, ${ }^{17}$ se ha integrado un corpus de tesis relativas a las máximas de la experiencia (ME), temática seleccionada por su representatividad del quehacer jurisdiccional, que descansa en las razones siguientes:

1. Ha estado presente en el tratamiento jurisprudencial desde la sexta época de la jurisprudencia mexicana, por lo que su uso y registro en el SJF es constante en el tiempo. ${ }^{18}$

2. Ha sido objeto de atención jurisprudencial en distintas materias: civil, penal, laboral, fiscal, etcétera, por lo que su uso es transversal.

3. Las tesis han sido generadas por los distintos órganos facultados para crear jurisprudencia (art. 217, LA): Tribunales Colegiados de Circuito, Plenos de Circuito y SCJN, de manera que su manejo por estos operadores es extendido, a la vez que indiferente respecto de cada uno en lo particular.

4. La búsqueda en el SJF arroja un corpus manejable de tesis, a diferencia de si se trabajara con un concepto de mayor calado (por ejemplo, "libertad", "propiedad" o "fraude").

5. Está presente tanto en tesis aisladas como en jurisprudenciales, por lo que las observaciones que se desprendan del análisis pueden tener el alcance de

16 Incluso, cabe cuestionarse si en su ensamble tecnológico, en el cotidiano escenario de cargas de trabajo y escasez de personal, hay lugar para un ejercicio detenido y ponderado de prudencia judicial o, más bien, el estudio de la jurisprudencia se limita a la búsqueda digital de los precedentes para resolver cualquier caso y, una vez leída la prosa del criterio, decidir en el momento su parentesco con la litis para, acto seguido, realizar un ejercicio de corta y pega en las consideraciones de la resolución. No obstante, abordar este último par de preguntas requeriría un enfoque de acompañamiento en campo con los operadores jurisdiccionales que rebasa por mucho las posibilidades de este escrito, por lo que solo se dejan aqui anunciadas provisionalmente.

17 Al 1 de septiembre de 2018.

18 Sobre los intervalos de las épocas de la jurisprudencia mexicana véase: https://sjf.scjn.gob.mx/sjfsist/Paginas/wfContenido.aspx?control=Contenidos/ucNoticia\&file=NoticiaHistorica\&Info4=Info4 
comprender a la labor jurisdiccional de amparo en sentido amplio, sin detenerse en esa distinción formal sobre la obligatoriedad de los criterios.

6. Es un concepto que entraña su propia complejidad interpretativa (como se esboza más adelante) por lo que resulta ejemplificativo del tipo de tarea que se requiere de los tribunales, en general, que se encuentren con la necesidad de valerse de este tipo de conceptos de amplio rango semántico y de los tribunales federales de Amparo, en específico, que pretenden normar sus posibilidades de sentido para la observancia de aquellos, fijando su significado y desentrañando sus posibilidades de aplicación.

De ahí que las ME son un insumo de trabajo idóneo para los propósitos de este documento porque, por así decirlo, más que en analizar una temática de la jurisprudencia, se enfocan en la jurisprudencia en sí, a través del estudio de las tesis que le dan cuerpo.

De esta manera, al limitar el rango de búsqueda a partir de la Novena y la actual Décima Época (en aras de analizar tesis realmente aplicables por los juzgadores, ya que las previas tienen un valor más bien histórico), al momento de realizar esta investigación (octubre de 2018) e introducir en el motor de búsqueda del SJF la voz "máximas de la experiencia" se despliega un total de 65 registros, los cuales, tras su depuración (registros repetidos o que realmente no versan sobre las $\mathrm{ME} \mathrm{a}$ pesar de referirlas) arrojan un total de 60 tesis, que conforman el corpus de trabajo.

A continuación se muestran los hallazgos más representativos sin que se haga mención a la cantidad de tesis en que se encuentran o de los porcentajes a los que corresponden respecto del total pues su representatividad estriba, más que en su mayor o menor preponderancia numérica, en el contraste de sus posibilidades de uso, en las distintas funciones que, en la efectiva práctica judicial, los TrAm asignan a este concepto.

De ahí que tampoco se hace referencia a todos los criterios en que se ha detectado una función particular, sino solo a un par de ellos para ejemplificar ese tratamiento, o sea, para mostrar que las tesis si despliegan la función que en el presente trabajo se les atribuye, en aras de no fatigar la lectura -para lo que se procura la cita textual solo de la porción de la tesis en cuestión, cita que, por lo demás, se estima necesaria para evidenciar que la interpretación que aquí se efectúa está apegada al uso dado por los TrAm.

\section{MÁXIMAS DE LA EXPERIENCIA Y VALORACIÓN PROBATORIA}

\subsection{Para la apreciación de pruebas}

Al margen de los aspectos que, a continuación, se refieren puntualmente a cada prueba en particular, además de que las tesis de este apartado (decididamente, la 
mayoria del corpus) tienen como finalidad esencial normar la justipreciación probatoria de los jueces, deben destacarse otros aspectos de interés que están presentes de manera consistente, con independencia de la materia en específico a la que las tesis están referidas (civil, penal, fiscal, administrativa, laboral), relativos a:

- Las apelaciones al juzgador para que tome en cuenta las "particularidades" de cada litigio explicitando referencias del tipo: "en relación con las circunstancias del caso", ${ }^{19}$ "apreciando los hechos en conciencia" ${ }^{20}$, "con los elementos existentes en autos", "con base en los elementos y circunstancias concurrentes en cada caso, ${ }^{22}$ "tomando en cuenta las peculiaridades de cada caso", ${ }^{23}$ etcétera.

- Que se indique que la prueba en cuestión debe ser valorada en "unión con el resto de las probanzas" de autos, a través de referencias como "no deben analizarse de forma aislada, sino en conjunto con los demás elementos de prueba”"24, "los medios de prueba valorados y admitidos serán valorados en su conjunto por el juzgador", ${ }^{25}$ "lo que debe llevarse a cabo conjunta y sistemáticamente, ${ }^{26}$ "si en su conjunto son suficientes para acreditar el hecho", ${ }^{27}$ etcétera.

Con tales precisiones, los usos de las ME para la valoración de pruebas son:

a. Referencia genérica a la potestad judicial de valoración de pruebas

Hay tesis que más que ahondar en las implicaciones de una prueba en particular contienen un pronunciamiento genérico del TrAm sobre la potestad

19 "Extinción de dominio. La procedencia lícita del bien materia de la acción relativa puede ser acreditada por el afectado con los elementos de prueba o indicios que tenga a su alcance y que, razonablemente, conduzcan al juzgador a la convicción de que su origen es legal”. Décima Época, Primera Sala, tesis de jurisprudencia, materia civil, tesis: 1a./17/2015 (10a.), registro: 2008880.

20 "Conducta procesal de las partes en el procedimiento laboral. Las juntas están facultadas para valorarla identificando los actos $\mathrm{u}$ omisiones que permitan o impidan llegar al conocimiento de la verdad”. Novena Época, Tribunales Colegiados de Circuito, tesis aislada, materia laboral, tesis: XVIII.10.9 L, registro 162187.

21 "Cuantía del juicio. actos en los que produce efectos y forma de determinarla". Novena Época, Tribunales Colegiados de Circuito, tesis aislada, materia civil, tesis: I.4o.C.292 C, registro: 163839.

22 "Resarcimiento del daño consistente en la privación del uso y disfrute de un bien. Se logra mediante el pago de una renta”. Novena Época, Tribunales Colegiados de Circuito, tesis aislada, materia civil, tesis: I.4o.C.248 C, registro: 165411.

23 "Acta de visita domiciliaria. La cita en esta de un número diferente de la finca donde se ubica el domicilio del contribuyente no genera su nulidad, si existen elementos suficientes para establecer que se trata de un error mecanográfico". Novena Época, Tribunales Colegiados de Circuito, tesis aislada, materia administrativa, tesis III.4o.A.16 A, registro: 172637.

24 "Prueba pericial en materia de topografia. La circunstancia de que no se indique en los dictámenes correspondientes los instrumentos utilizados por los peritos es insuficiente para desestimarlos (legislación del estado de coahuila)". Novena Época, Tribunales Colegiados de Circuito, tesis de jurisprudencia, materia civil, tesis: VIII.5o. J/1, registro: 170214.

25 "Prueba pericial, valoración de LA. Sistemas". Novena Época, Tribunales Colegiados de Circuito, tesis de jurisprudencia, materia civil, tesis I.3o.C. J/33, registro: 181056.

26 "Control judicial de los actos de elevada complejidad técnica emitidos por el instituto federal de telecomunicaciones. Sus limites y características”. Décima Época, Tribunales Colegiados de Circuito, tesis aislada, materia constitucional, tesis: I.1o.A.E.206 A (10a.), registro: 2013920.

27 "Inmatriculación de bienes. Para probar la posesión en concepto de dueño es admisible el testimonio de testigos que no reúnan la alta calidad que, de modo preferente, se prevé en el procedimiento respectivo”. Décima Época, Primera Sala, tesis aislada, materia civil, tesis 1a. XIII/2017 (10a.), registro: 2013490. 
probatoria con que se encuentra investido el juzgador en cuanto juzgador (decidir su alcance, concederle o no eficacia, etcétera), para el que involucran a las ME con tres variantes:

- Al hacer referencia literal a una disposición normativa en donde las ME se fijan como parte de un lenguaje formulario sobre la valoración de pruebas, en el sentido de que "De acuerdo con el artículo 513 del Código Procesal Civil para el Estado [de Coahuila], el juzgador está obligado a realizar el análisis y valoración de las pruebas en su conjunto, conforme a la sana crítica y las máximas de la experiencia”. ${ }^{28}$

- Considerándolas a partir de la interpretación de un artículo en el que no se utiliza ese tipo de fórmula probatoria: "El citado precepto [artículo $1301 \mathrm{del}$ Código de Comercio] al establecer que la fe de los demás juicios periciales, incluso el cotejo de letras, será calificado según las circunstancias [...] adopta el sistema de prueba libre que no implica ausencia de reglas ni subjetivismo, capricho o arbitrariedad del juzgador para decidir el valor de cada peritaje, sino la exigencia de aplicar criterios racionales, basados en las reglas de la lógica y las máximas de la experiencia”. ${ }^{29}$

- Sin referencia a una norma específica: "la valoración debe ser racional, es decir, aquella que en su práctica emplea elementos o reglas racionales, lógica, máximas de la experiencia, método científico y pensar reflexivo, para interpretar y valorar los resultados de la aportación de datos de prueba". ${ }^{30}$

28 "Prueba pericial en materia de topografia..., cit. En el mismo sentido: “...destaca el artículo 21 [de la Ley de Justicia para Menores del Estado de Querétaro] que señala que los hechos y circunstancias pertinentes para la adecuada solución del caso habrán de ser probados por cualquier medio de prueba y que estos serán valorados por los Jueces según la sana crítica, observando las reglas de la lógica, los conocimientos científicos y las máximas de la experiencia". "Procedimiento administrativo contra menores. En la audiencia prevista en el artículo 67 de la ley de justicia para menores para el estado de Querétaro, tanto el ministerio público, en su calidad de parte acusadora, como la defensa de los menores y estos a través de quien ejerza su patria potestad, tutela o custodia, pueden ofrecer y desahogar las pruebas que estimen necesarias". Novena Época, Tribunales Colegiados de Circuito, tesis aislada, materia penal, tesis: XXII.10.24 P, registro: 166599.

29 "Prueba pericial en el juicio mercantil. El artículo 1301 del Código de Comercio no viola el debido proceso en su vertiente del derecho a la prueba”. Décima Época, Primera Sala, tesis aislada, materia constitucional, tesis 1a. LXXV/2017 (10a.), registro: 2014695. Igualmente: "[según el artículo 211 del Código Federal de Procedimientos Civiles] la eficacia de la prueba pericial quedará a la prudente apreciación de aquél. Conforme a esta regulación la apreciación de la prueba pericial está comprendida dentro del sistema denominado de libre valoración, que se funda en la sana crítica, la cual consiste en una operación que, sirviéndose de las reglas de la lógica, relaciona el conjunto de probanzas, las máximas de la experiencia, el correcto entendimiento humano y los conocimientos científicos especializados". "Prueba pericial en el juicio contencioso administrativo federal. Aspectos que determinan la eficacia de los dictámenes relativos (aplicación supletoria del Código Federal de Procedimientos Civiles)". Décima Época, Tribunales Colegiados de Circuito, tesis aislada, materia administrativa, tesis: I.1o.A.E. 148 A (10a), registro: 2011749.

30 "Auto de vinculación a proceso. Test de racionalidad que procede aplicar para el estudio de los datos de prueba, a partir de los cuales puede establecerse que se ha cometido un hecho imputado como delito [modificación de la tesis XVII.1o.P.A.31 P (10a.)]”. Décima Época, Tribunales Colegiados de Circuito, tesis aislada, materia penal, tesis XVII.1o.P.A.52 P (10a.), registro 2015954. De la misma manera: la "valoración de la prueba es una actividad intelectiva exclusiva de la autoridad responsable, al determinar con base en sus conocimientos de derecho y en las máximas de la experiencia, sobre declaraciones, hechos, personas, cosas, documentos, huellas y lo demás que como prueba se hubiera presentado al proceso, para valorar el auto de formal prisión". "Auto de formal prisión, facultades de los órganos de control constitucional respecto de la licitud, valor jurídico 


\section{b. Testimonial}

Respecto de esta prueba las tesis aluden a las ME para valorar la credibilidad del testigo y, en función de ello, su alcance probatorio, toda vez que "es legal que la autoridad responsable pondere, conforme a las reglas de la lógica y las máximas de experiencia, si dicho testigo se condujo de manera libre y espontánea", ${ }^{31}$ y que a partir de tales ME respecto de la testimonial el juzgador "está obligado a estudiar una serie de aspectos concomitantes a ella no circunscritos exclusivamente a la calidad del testigo como persona digna de crédito, sino extendidos a todo el contexto de lo declarado por él". ${ }^{32}$

\section{c. Documental}

Las tesis que versan sobre esta prueba implican a las ME para valorar alguna cualidad particular en el documento a fin de que puedan surtir efectos probatorios plenos (análogos al documento público, tasado), ya que "les da una categoría propia dentro de los documentos privados que conduce a una valoración específica, caso por caso, con apego a las reglas de la lógica y a las máximas de la experiencia que resultan aplicables a las circunstancias concurrentes”, ${ }^{3}$ en virtud de que "solo tiene efectos de un medio de prueba, y como tal, debe ser valorado por el juez de la causa reivindicatoria, con apego a las reglas de la lógica y las máximas de la experiencia”. ${ }^{34}$

\section{d. Pericial}

El uso de las ME para esta prueba implica un camino de ida y vuelta: de un lado, que a través de ellas el juez valore la prueba y, del otro, que las ME que se contengan en el dictamen orienten su conocimiento para resolver el caso (con lo que parece que las $\mathrm{ME}$ adquieren un matiz, para no ser tanto un conocimiento genérico y común, sino el propio de un área particular del quehacer humano).

En el primer escenario, el juez otorga a la pericial el valor probatorio "que estime conveniente acudiendo para ello a las reglas de la experiencia y hechos notorios que constituyen reglas o verdades de sentido común y la sana critica" ${ }^{35}$

y alcance demostrativo de las pruebas”. Décima Época, Tribunales Colegiados de Circuito, tesis aislada, materia penal, tesis: XI.P.5 P (10a), registro: 2011412.

31 "Testigo único. Su declaración tiene valor probatorio, si además de existir condiciones subjetivas de credibilidad, es confirmada por las circunstancias y particularidades aportadas por diversos medios de prueba (legislación del estado de Chihuahua)”. Novena Época, Tribunales Colegiados de Circuito, tesis aislada, materia penal, tesis: XXII.10.24 P, registro: 166599.

32 "Testigos. Su valoración debe hacerse tomando en cuenta la integridad del testimonio y no la calidad de aquellos (legislación del estado de Michoacán)”. Novena Época, Tribunales Colegiados de Circuito, tesis aislada, materia civil, tesis: XI.1o.T.Aux.15 C, registro: 162683.

33 "Expediente clínico. Es documento privado sujeto para su valoración a requisitos establecidos en regulación especial”. Novena Época, Tribunales Colegiados de Circuito, tesis aislada, materia civil, tesis: I.4o.C.154 C, registro: 168924.

34 "Usucapión, valor probatorio de la sentencia estimatoria. Frente a quienes no participaron en la contienda”. Novena Época, Tribunales Colegiados de Circuito, tesis aislada, materia civil, tesis I.4o.C. 159 C, registro: 168748 .

37035 "Prueba científica. Su justificación y validez en la resolución de conflictos jurídicos”. Décima Época, Tribunales Colegiados de Circuito, tesis aislada, materia administrativa, tesis: I.4o.A.16 K (10a.), registro: 2003363. 
puesto que "si considera que las conclusiones de los peritos contrarian normas generales de la experiencia o hechos notorios o una presunción de derecho o cosa juzgada o reglas elementales de la lógica [...] puede rechazarlo aunque emane de dos peritos en perfecto acuerdo". ${ }^{36}$

Respecto del segundo escenario, el valor de la pericial depende de que en su metodologia se describan los procedimientos empleados para el examen de las cuestiones sometidas a calificación " $\mathrm{y}$, en su caso, hagan referencia a los principios, máximas de la experiencia o conocimientos especializados que se apliquen", ${ }^{37}$ y de que el conocimiento especializado que puede obtenerse de los métodos científicos o de procedimientos expertos haga "participes a los juzgadores de la información derivada de las leyes, teorías, modelos explicativos, máximas de la experiencia y destrezas, incluso de presunciones, todos ellos correspondientes a las diversas ciencias que se rigen por distintas metodologias". ${ }^{38}$

\section{e. Presuncional}

Las tesis que se refieren a esta prueba utilizan las ME para dos fines: 1) para la construcción de la inferencia que vincula el conocimiento conocido con el desconocido (que se busca establecer a partir de la presunción) con base en la acreditación de la inferencia "que se funda en la eficiencia y suficiencia del hecho secundario, cuya existencia ha sido probada, lo que por lo general, implica acudir a máximas de la experiencia solventes y a argumentos basados en la sana crítica", 39 toda vez que "la inferencia lógica debe sustentarse en máximas de experiencia, es decir, en una idea de razonabilidad [...] a partir de una comprensión razonable de la realidad y del asunto concreto". ${ }^{40}$

El segundo se presenta cuando el juzgador tiene que interpretar las presunciones probatorias establecidas en ley, puesto que, por ejemplo, "el valor de las presunciones humanas depende de la fuerza que les proporcionen las reglas de la lógica y las máximas de la experiencia aplicables para su valoración”, ${ }^{41}$ o que en la ley se "recogen experiencias derivadas de prácticas que se dan con un cierto margen de generalidad o reiteración, lo que se conoce como 'máximas de la experiencia' que dada su idoneidad el legislador las positiviza, recogiéndolas en el texto con ese carácter" ${ }^{42}$

36 "Prueba pericial, valoración de la ...", cit.

37 "Prueba pericial en el juicio contencioso administrativo federal. Requisitos de fondo de los dictámenes relativos (aplicación supletoria del Código Federal de Procedimientos Civiles)”. Décima Época, Tribunales Colegiados de Circuito, Tesis Aislada, materia administrativa, tesis: I.1o.A.E.147 A (10a.), registro: 2011750.

38 "Prueba pericial científica. Su objeto y finalidad". Décima Época, Tribunales Colegiados de Circuito, tesis aislada, materia administrativa, tesis I.1o.A.E.45 K (10a.), registro: 2010576.

39 "Presunciones. Valor probatorio en distintos grados". Novena Época, Tribunales Colegiados de Circuito, tesis aislada, materia civil, tesis: I.4o.C.161 C, registro: 16882.

40 "Prueba presuncional humana en el juicio laboral. Estándares que deben seguirse para analizar su actualización”. Décima Época, Tribunales Colegiados de Circuito, tesis aislada, materia laboral, tesis: XI.1o.A.T.36 L (10a.), registro: 2014187.

41 "Presunciones. Valor probatorio en distintos grados". Novena Época, Tribunales Colegiados de Circuito, tesis aislada, materia civil, tesis: I.4o.C.161 C, registro: 168827.

42 "Presunción jurídica. Su noción en materia tributaria”. Décima Época, Tribunales Colegiados de Circuito, tesis aislada, materia administrativa, tesis: I.4o.A.57 A (10a.), registro: 2003696. 


\subsection{Para colmar lagunas normativas}

Un supuesto diverso, aunque emparentado con el antecedente, tiene lugar cuando los TrAm generan tesis en las que se valen de ME para superar el silencio legal que advierten sobre algún aspecto vinculado con la valoración de la prueba, como se aprecia respecto de la LA que, en su artículo 119, establece la forma en que debe ofrecerse la pericial (prestando un cuestionario que, tras ser calificado, será respondido por el perito), "sin embargo, en dicha ley ni en su ordenamiento supletorio, el Código Federal de Procedimientos Civiles, se prevén las prescripciones necesarias para regular la forma en que ese medio de prueba habrá de evaluarse, lo que hace necesario recurrir a las máximas de la experiencia para su complementación, que se basan en aspectos prácticos de razonabilidad”. ${ }^{43}$

O como también sucede respecto del silencio sobre la carga de la prueba en el supuesto de la liquidación de la sociedad conyugal de un segundo matrimonio que ha sido declarado nulo: "por lo que, en tales casos, corresponde la carga de la prueba a la cónyuge del matrimonio subsistente [...] porque las máximas de la experiencia y la sana crítica permiten discernir [...] que la persona que se casa por segunda vez, es porque resultó disfuncional su matrimonio y decide hacer vida en común con diversa persona aun sin divorciarse, ya sea por desconocimiento de las leyes y consecuencias jurídicas o por alguna otra circunstancia". ${ }^{44}$

\subsection{Para obtener conclusiones fácticas}

En ese escenario específico, las tesis tienen dos matices: por una parte, a partir de las ME es posible establecer una especie de "potestad abstracta" para que el juzgador tome una decisión sin sustento en actuaciones probatorias de las partes (ni generadas por él mismo de manera oficiosa) y, por otra, el juzgador aplica directamente la máxima para tener por actualizada una hipótesis normativa.

Ejemplo del primer supuesto se presenta cuando el juzgador establece que se actualiza la posibilidad de emplazar nuevamente a un testigo no localizado por un error en el domicilio proporcionado por la parte interesada: "atendiendo a las reglas de la lógica, de la sana crítica y de las máximas de la experiencia [...] de estimar que subsiste el interés legitimo en su desahogo y que no se trata de retardar el procedimiento [...] se proveerá a la citación de los testigos nuevamente". ${ }^{45}$

43 "Prueba pericial en el amparo. Estándar para su admisibilidad”. Décima Época Tribunales Colegiados de Circuito Tesis Aislada Materia Común Tesis: I.1o.A.E.66 K (10a.), registro: 2012776.

44 "Liquidación de la sociedad conyugal del segundo matrimonio declarado nulo. La carga de la prueba para excluir los bienes inventariados para tal efecto, corresponde a la consorte del subsistente, que asevera son los mismos que pertenecen al caudal común conformado con el marido que contrajo nupcias dos veces”. Décima Época, Tribunales Colegiados de Circuito, tesis aislada, materia civil, tesis: I.110.C.58 C (10a.), registro: 2007029.

45 "Prueba testimonial en el procedimiento laboral. Incomparecencia de los testigos citados a solicitud del oferente, cuando el domicilio proporcionado es incorrecto. La junta, apreciando cada caso, puede, de manera fundada y motivada, declarar de plano la deserción de la prueba o requerir al oferente para que proporcione el domicilio correcto". Novena Época, Segunda Sala, tesis de jurisprudencia, materia laboral, tesis: 2a./J. 79/99, registro: 193616. 
El segundo escenario tiene lugar, por ejemplo, sobre la posible actualización del supuesto de recusación cuando el juez de amparo recibe a una de las partes en su despacho, pues: "las máximas de la experiencia demuestran que la mayoría de los titulares de los juzgados y tribunales federales [...] reciben a todas las partes en su despacho y no por esa circunstancia pueda pensarse que se pierda o al menos se comprometa la imparcialidad en el juicio por quien debe resolverlo". ${ }^{46}$

\subsection{A fin de establecer un parámetro objetivo de verdad para valoración de pruebas}

En ciertas tesis se concibe a las ME como conocimientos ajenos a controversia, de ahí que, con la fuerza de hechos notorios, sirvan para sustentar con pretensiones de objetividad las afirmaciones que haga el juzgador sobre los hechos del caso, pues "es evidente que se deben aprovechar las 'máximas de la experiencia', que constituyen reglas de vida o verdades del sentido común" ${ }^{47}$ y para lo cual "se debe de contar con la figura conocida como 'máximas de la experiencia', que son las reglas de vida o verdades del sentido común que contribuyen de un modo eficaz a la formación de la presunción judicial”.

\subsection{Para sustentar una decisión razonable}

Diversas tesis vinculan las ME con un apoyo al que debe atender el juzgador para que la decisión a la que arribe sea razonable; al repecto, pueden distinguirse dos clases de referencias:

- Lo razonable como vinculado a evitar arbitrariedad en la decisión discrecional: la utilización de las ME buscan inhibir el subjetivismo en la valoración probatoria, pues "en ciertos casos, la enunciación, descripción, interpretación y decisión de elementos fácticos o, incluso subjetivos, componentes de

46 "Impedimento por recusación previsto en el artículo 51, fracción VIII, de la ley de amparo. No se actualiza por el hecho de que el denunciante del delito que se le imputa al quejoso acuda a solicitar audiencia ante el juez de distrito o los magistrados de circuito que conocen del juicio, y estos lo reciban”. Décima Época, Tribunales Colegiados de Circuito, tesis aislada, materia común, tesis I.9o.P.113 P (10a.), registro 2011811. En el mismo tenor, en el caso de un error de prohibición vencible en el delito de privación ilegal de la libertad respecto de quien opera un centro contra las adicciones que no tiene permiso para operar como tal, pues "las máximas de la experiencia nos enseñan que existen lugares en donde se trata este tipo de problemas -alcoholismo y drogadicciónlos cuales se anuncian por diversos medios de comunicación; [...] lo que le impedia considerar que su conducta era antijurídica, pues no existía motivo alguno que le hiciera pensar que cometía un delito, puesto que dichos comportamientos se estiman como estereotipos de comportamiento lícito en sociedad". "Error de prohibición indirecto e invencible. Se actualiza esta causa de inculpabilidad prevista en el artículo 29, fracción viii, inciso b), del Código Penal para El Distrito Federal, aplicable para la ciudad de México, en su texto anterior a la reforma de 18 de diciembre de 2014, cuando el inculpado actúa creyendo que un ordenamiento le concedía permiso para mantener privado de su libertad al sujeto pasivo dentro de un 'anexo' de tratamiento para alcoholismo y drogadicción”. Décima Época, Tribunales Colegiados de Circuito, tesis aislada, materia penal, tesis: I.9o.P.126 P (10a.), registro: 2013701.

47 "Pruebas. Su valoración en términos del artículo 402 del código de procedimientos civiles para el distrito federal”. Décima Época, Tribunales Colegiados de Circuito, tesis aislada, materia civil, tesis: I.5o.C. J/36 (10a.), registro: 160064. 
infracciones o delitos, pueden requerir el empleo de márgenes de discrecionalidad y conocimientos especializados, los cuales deben sujetarse a criterios de razonabilidad", ${ }^{48}$ como sucede, por ejemplo, con la determinación y moderación del importe de los daños y perjuicios "que no deben ser arbitrarias sino sujetas a criterios objetivos y racionales [...] Los elementos que deben servir de sustento para la cuantificación, son las constancias del expediente en el cual se emitió la ejecutoria sujeta a cumplimiento, los hechos notorios que sirvan al efecto y su valoración con apego a las reglas de la lógica y las máximas de la experiencia, como corresponde a la apreciación de todo material probatorio". ${ }^{49}$

- Lo razonable como vinculado a un cálculo de probabilidades: toda vez que la valoración del material probatorio "debe ser racional, es decir, aquella en que su práctica emplea elementos o reglas racionales, máximas de la experiencia, método científico y pensar reflexivo, para valorar los resultados de la aportación de los datos de prueba [...] que no es más que evaluar el grado de probabilidad, con fundamento en los medios disponibles, si puede considerarse como verdadera una hipótesis sobre los hechos". ${ }^{50}$

\section{MÁXIMAS DE LA EXPERIENCIA Y CORRELACIONES CON OTROS CONCEPTOS DE VALORACIÓN PROBATORIA}

Para estas alturas, el lector ya habrá advertido que las tesis utilizadas de ejemplo para la valoración de las pruebas con independencia de la materia sobre la que versen, y al margen de las funciones en que han sido catalogadas, hacen referencia a las ME asociándolas de manera conjunta (y ciertamente heterogénea) con otros conceptos que también involucran saberes útiles para que el juzgador valore las pruebas: método científico, reglas de la lógica, pensar reflexivo, sana crítica, prueba libre, sentido común.

Más aún, en las tesis del corpus se advierte que los TrAm no solo vinculan las ME con diversos conceptos, sino que también lo hacen de diversa manera, a saber, en dos tipos de asociación semántica.

48 "Prueba pericial en el juicio mercantil. El artículo 1301 del código de comercio no viola el debido proceso en su vertiente del derecho a la prueba”. Décima Época, Primera Sala, tesis aislada, materia constitucional, tesis: 1a. LXXV/2017 (10a.), registro: 2014695.

49 "Condena al cumplimiento de obligaciones de hacer. Sustitución por pago de daños y perjuicios. Procedimiento ejecutivo para su cumplimentación forzosa (Interpretación del artículo 518 del Código de Procedimientos Civiles para el Distrito Federal)". Novena Época, Tribunales Colegiados de Circuito, tesis aislada, materia civil, tesis: I.4o.C.178 C, registro: 167958.

50 "Auto de vinculación a proceso. Test de racionalidad que procede aplicar para el estudio de los datos de prueba, a partir de los cuales puede establecerse que se ha cometido un hecho imputado como delito [modificación de la tesis XVII.1o.P.A.31 P (10a.)]”. Décima Época, Tribunales Colegiados de Circuito, tesis aislada, materia penal, tesis: XVII. 1o.P.A.52 P (10a.), registro 2015954. En el mismo tenor: "Debe reputarse para efectos de la ley -la presunta enajenación de mercancías adquiridas y no registradas en la contabilidad-por ser realmente posible o probable su realización cuando así lo demuestren las máximas de la experiencia y el conocimiento fáctico sobre el que se pretende actuar". "Presunción de enajenación de bienes prevista en el artículo 60 del Código Fiscal de la Federación. Sus características”. Décima Época, Tribunales Colegiados de Circuito, tesis aislada, materia administrativa, tesis: I.4o.A.56 A (10a.), registro: 2003691. 
a. Relaciones de coordinación conceptual: la asociación de las ME con otros conceptos de incidencia probatoria se presenta de manera lineal e indeterminada, sin que haya distinciones de jerarquía de un concepto respecto de otro para efectos de establecer cuál de ellos tiene preferencia o preponderancia en la valoración de la prueba, de modo que parece que los conceptos se encuentran en el mismo escalafón de pertinencia o utilidad para que el juzgador se valga de ellos.

b. Relaciones de subsunción conceptual: en contrapartida a la coordinación, las ME aparecen supeditadas a otro concepto que condiciona la valoración probatoria; el concepto preponderante es una especie de continente del que las ME y otros conceptos son sus componentes o contenido.

Dado que el esquema de enunciación de las tesis que acto seguido se refieren es esencialmente el mismo, esto es, en esencia ponen en conjunto los conceptos sin mayores indicaciones interpretativas sobre la forma en que interactúan entre ellos -al margen de las aludidas distinciones de coordinación y subordinación-, es que únicamente se cita la porción específica del criterio que permite advertir la variante de uso en particular sin hacer mayor comentario en lo individual, para ser retomados globalmente en el apartado siguiente.

Dicho lo cual, según este criterio de clasificación, los usos de las tesis jurisprudenciales son:

\subsection{Relaciones de coordinación}

a. Lógica y ME: en estas relaciones las ME aparecen vinculadas a un concepto "lógico" (del tipo reglas de la lógica o principios lógicos) "para determinar, razonadamente, conforme a las reglas de la lógica y las máximas de la experiencia, si en su conjunto son suficientes para acreditar el hecho". ${ }^{1}$

b. Lógica, ME y conocimiento científico: "esa facultad que constitucionalmente le ha sido dada y que se encuentra obligado a cumplir, aplicando la lógica, los conocimientos científicos y las máximas de la experiencia”. ${ }^{52}$

51 “Dictámenes periciales sobre accidentes de tránsito rendidos en procedimientos de averiguación previa o de justicia cívica. Son indicios relevantes que pueden alcanzar la eficacia necesaria para acreditar en el juicio civil la existencia, origen y monto de los daños generados por la colisión". Décima Época, Tribunales Colegiados de Circuito, tesis aislada, materia civil, tesis: I.3o.C.251 C (10a.), registro: 2012752.

52 "Procedimiento abreviado. El hecho de que el inculpado opte por esta forma especial de terminación anticipada, admita los hechos que se le atribuyen y esté de acuerdo con la cantidad que el ministerio público precisó en su acusación por concepto de reparación del daño, no impide que el juez de garantía valore las pruebas y concrete la imposición de dicha sanción pecuniaria, sin que se exceda del monto que conformó la imputación (nuevo sistema de justicia penal en el estado de Chihuahua)". Décima Época, Tribunales Colegiados de Circuito, tesis de jurisprudencia, materia penal, tesis: XVII.1o.P.A. J/11(10a.), registro: 2010642. 
c. Lógica, sana crítica y ME: "atendiendo a las reglas de la lógica, de la sana crítica y a las máximas de la experiencia, la Junta podrá, atendiendo a las circunstancias del caso particular, dar vista al oferente". ${ }^{53}$

d. Sana crítica y ME: "el juzgador está obligado a realizar el análisis y valoración de las pruebas en su conjunto, conforme con la sana crítica y las máximas de la experiencia" 54

e. Conocimiento jurídico y ME: la "valoración de la prueba, es [...] una actividad intelectiva exclusiva de la autoridad responsable, al determinar, con base en sus conocimientos de derecho y en las máximas de la experiencia”. ${ }^{55}$

f. ME, hechos notorios y sana crítica: "el juzgador le otorgará, según su prudente estimación, el valor que estime conveniente, atendiendo para ello a las máximas de experiencia y hechos notorios o públicos que constituyen reglas o verdades de sentido común y la sana crítica”. ${ }^{56}$

\subsection{Relaciones de subordinación}

a. Las ME subordinan a la lógica: "la inferencia lógica debe sustentarse en máximas de la experiencia, es decir en una idea de razonabilidad, de forma que el vínculo entre hechos base $u$ hechos consecuencia debe construirse coherentemente a partir de una comprensión razonable de la realidad y del asunto concreto". ${ }^{57}$

b. La sana crítica subordina ME y lógica: "todos los hechos y circunstancias pertinentes para la adecuada solución del caso habrán de ser probados por cualquier medio de prueba y que estos serán valorados por los Jueces según la sana crítica, observando las reglas de la lógica, los conocimientos científicos y las máximas de la experiencia". ${ }^{58}$

c. La libre convicción subordina a la sana crítica, la que a su vez subordina a ME y lógica: "las pruebas de libre convicción son las que se fundan en la sana critica, y que constituyen las reglas del correcto entendimiento humano. En estas interfieren las reglas de la lógica con las reglas de la experiencia del juez, que contribuyen a que pueda analizar la prueba con arreglo a la sana razón y a un conocimiento experimental de las cosas". ${ }^{59}$

d. La sana crítica subsume a la libre valoración, la que a su vez subsume a ME, lógica y conocimiento científico: "la sana crítica implica un sistema de valoración de pruebas libre, pues el juzgador no está supeditado a normas rígi-

53 "Prueba testimonial en el procedimiento laboral. Incomparecencia de los testigos..., cit.

54 "Prueba pericial en materia de topografia...", cit.

55 "Auto de formal prisión, facultades de...", cit.

56 "Prueba circunstancial. El artículo 261 del código de procedimientos penales para el distrito federal, no viola la garantía de debido proceso". Décima Época, Primera Sala, tesis aislada, materia constitucional, tesis: 1a. CCLXXIII/2012 (10a.), registro: 2002370.

57 "Prueba presuncional humana en el juicio laboral...", cit.

58 "Procedimiento administrativo contra menores...", cit.

59 "Prueba testimonial en el procedimiento laboral...", cit. 
das que le señalan el alcance que debe reconocerse en aquellas; es el conjunto de reglas establecidas para orientar la actividad intelectual en la apreciación de estas, y una fórmula de valoración en la que se interrelacionan las reglas de la lógica, los conocimientos científicos y las máximas de la experiencia”. ${ }^{60}$

e. La libre convicción subordina la sana critica, la que subordina a la lógica, que a su vez subordina a las ME, el correcto entendimiento humano y el conocimiento científico: "la apreciación de la prueba pericial está comprendida dentro del sistema de libre valoración, que se funda en la sana crítica, la cual consiste en una operación que sirviéndose de las reglas de la lógica, relaciona el conjunto de probanzas, las máximas de la experiencia, el correcto entendimiento humano y los conocimientos científicos especializados". ${ }^{61}$

f. La libre convicción subordina a la lógica que a su vez subordina a las ME: "la valoración libre de la prueba circunstancial no equivale a la valoración de indicios carentes de razonamiento alguno [...] la eficacia de la prueba circunstancial disminuirá en la medida en que las conclusiones tengan que obtenerse a través de mayores inferencias y cadenas de silogismos, ante lo cual, la inferencia lógica debe sustentarse en máximas de la experiencia”. ${ }^{62}$

g. La libre valoración subordina a reglas de la razón y experiencia: “conforme al principio de libre valoración probatoria que rige en los juicios civiles, las pruebas deben ponderarse en su conjunto, con base en las reglas de la razón y de la experiencia”. ${ }^{63}$

Sin que, como ya se anticipaba (y se espera que ya para este momento ello se haya demostrado), los criterios de clasificación descansen en la explicitación o no de las ME por parte de los TrAm u otros conceptos asociados, pues sin negar que algunos de los TrAm pudieran tener como finalidad al generar una tesis esa labor de explicitación conceptual, las regularidades referenciales están presentes aunque algunas tesis las definan, ${ }^{64}$ otras las caractericen, tangencialmente, $\mathrm{u}$ otras tantas no lo hagan en modo alguno.

60 "Pruebas en el juicio oral. Concepto de sana crítica y máximas de la experiencia para efectos de su valoración (interpretación del artículo 592 bis del código de procedimientos penales del estado de Nuevo León)”. Décima Época, Tribunales Colegiados de Circuito, tesis aislada, materia penal, tesis: IV.1o.P.5 P (10a.), registro: 2002373.

61 "Prueba pericial en el juicio contencioso administrativo federal..., cit.

62 "Prueba indiciaria o circunstancial. El juzgador debe explicar, en la sentencia correspondiente, el proceso racional a través del cual la estimó actualizada”. Décima Época, Primera Sala, tesis aislada, materia penal, tesis: 1a. CCLXXXVI/2013 (10a.), registro: 2004753.

63 "Dictámenes periciales sobre accidentes de tránsito rendidos en procedimientos de averiguación previa o de justicia cívica...”, cit.

64 Como muestra la tesis utilizada en el inciso d), de las relaciones de subordinación, que realiza varias precisiones que no inciden en las subsunciones conceptuales para las que sirvió de ejemplo: "Ahora bien, la sana crítica implica un sistema de valoración de pruebas libre, pues el juzgador no está supeditado a normas rígidas que le señalen el alcance que debe reconocerse a aquellas; es el conjunto de reglas establecidas para orientar la actividad intelectual en la apreciación de estas, y una fórmula de valoración en la que se interrelacionan las reglas de la lógica, los conocimientos científicos y las máximas de la experiencia, las cuales influyen de igual forma en la autoridad como fundamento de la razón, en función al conocimiento de las cosas, dado por la ciencia o por la experiencia, en donde el conocimiento científico implica el saber sistematizado, producto de un proceso de comprobación, y que por regla general es aportado en juicio por expertos en un sector 


\section{INTERPRETACIÓN DE HALLAZGOS: INSUMOS INTELECTUALES FRENTE A INSUMOS PRÁCTICOS PARA LA DECISIÓN PRUDENCIAL DE CASOS CONCRETOS}

La primera conclusión que se desprende de las clasificaciones efectuadas es que las ME tienen, al menos, dos ámbitos referenciales de uso (esto es, en las tesis en las que se les alude son usadas de dos formas):

- Uno perceptible a golpe de vista, vinculado con una dimensión orientadora sobre la aplicación de las $\mathrm{ME}$ para resolver un problema jurídico de incidencia probatoria (valorar una prueba específica, colmar una laguna procedimental, decidir obviando la prueba de parte, etcétera).

- Otro, un tanto subyacente, referido a la calidad de las ME como soporte de ese tipo de decisión, que está vinculado con otros "saberes" de los que el juzgador puede igualmente valerse (lógica, ciencia, sentido común, sana crítica, entre otros).

Así, las regularidades de la primera categoría permiten apreciar el rol de las $\mathrm{ME}$ en la justificación de la decisión judicial (para dotar de un argumento convincente al juez) mientras que las de la segunda involucran el estatuto epistemológico de las ME (para establecer las condiciones de posibilidad de esa verificación probatoria, a fin de indicar el proceso intelectivo que subyace a las funciones del primer apartado, que son su conclusión). Mientras que unas comprenden el cómo se justifica la decisión, las otras involucran el sobre qué se justifica.

Es también plausible que ambos roles se muestren íntimamente relacionados en la lectura de los criterios jurisprudenciales, lo que puede obedecer, al menos en parte, a la necesidad de una redacción compacta, según el mandato legal de que las tesis deben expresar sus consideraciones de manera sintética.

No obstante, parece que ello también obedeceria, más que a la inviabilidad de diferenciarlos en la redacción de los criterios (pues como hemos visto en la clasificación ello es posible), a una especie de mixtura por parte de los TrAm, o sea, a un uso indiferenciado de las ME, como un lugar común o tópico: ${ }^{65}$

específico del conocimiento; mientras que las máximas de la experiencia son normas de conocimiento general, que surgen de lo ocurrido habitualmente en múltiples casos y que por ello pueden aplicarse en todos los demás, de la misma especie, porque están fundadas en el saber común de la gente, dado por las vivencias y la experiencia social, en un lugar y en un momento determinados". "Pruebas en el juicio oral. Concepto de sana crítica y máximas de la experiencia para efectos de su valoración...", cit.

65 Entendiéndolo como "una actividad argumentativa en campos carentes de verdades necesarias y con fines pragmáticos. Lo que la tópica aporta es un conjunto de argumentos de carácter general y susceptibles de utilización alternativa, que proporcionan a la argumentación los puntos de partida necesarios para que pueda estructurarse en torno a un conjunto de criterios, reglas y enunciados comúnmente aceptados y base, por tanto, de la ulterior construcción dialógica o retórica de las verdades prácticas" (Juan Antonio García Amado, Teorías de la tópica jurídica, Perú, Palestra, 2018, p. 64). "La tópica pretende suministrar datos para saber cómo hay que comportarse en una situación 
a. Sea de un lugar común de lenguaje, de lo que son evidencia referencias formularias que unen "las reglas de la lógica, las máximas de la experiencia y los conocimientos científicos" lo que podría ser resultado de que las tesis hagan remisión, más o menos expresa, a textos legales que contienen ese tipo de enunciación sacramental, de ahí que, si existen variaciones en los conceptos asociados a las ME en las tesis, se deberia a variantes legales correlativas.

Sin embargo, en esta linea no se encontraría la explicación completa pues, como se ha visto, en otras tesis se alude en términos similares a normas en que las ME no se encuentran expresamente contempladas, ya sea porque refieren un sistema de valoración libre de la prueba (lo que, de manera peculiar, implicaría que como parte de ese esquema valorativo las ME se asocien "libremente" a otros conceptos, lo que deja la cuestión totalmente indeterminada) o, simplemente, porque en otras tesis más ni siquiera se hace referencia a texto normativo alguno.

Así, las múltiples posibilidades combinatorias de las ME con otros conceptos de incidencia probatoria parecen ir más allá de una cuestión puramente terminológica o de alguna especie de falta de pulcritud en el uso de los conceptos de este o aquel TrAm.

b. Sea de un lugar común de conocimiento, de lo que es ejemplo claro el que en las relaciones de coordinación se involucre -sin mayores distingos- a diferentes categorías de obtención de conocimiento probatorio que, incluso, en más de un contexto pueden y son antagónicas, como los conocimientos científicos y los de sentido común, o que se establezca una equivalencia, sin más, entre este y las ME.

De modo que, en la literalidad de las tesis de jurisprudencia, pareceria que cualquier método para generar conocimiento probatorio fuera equivalente, como si se tratara de piezas alternables (valen lo mismo para fundar un conocimiento probatorio cierto) o intercambiables (si no sirve la una, sirve la otra para tomar una decisión de derecho) con implicaciones jurídicas más o menos inocuas; lo cual, a todas luces, no es así; el proceso judicial involucra, justamente, un fuerte componente de discernimiento sobre la pertinencia de métodos y corrección de resultados probatorios. No obstante, si esa complejidad es tan obvia en el caso concreto, ¿por qué su referenciación es tan, aparentemente, superficial al vincular de manera lineal (e indiscriminada) las metodologias de prueba, esto es, por qué esa complejidad está tan sobrentendida?

Lo anterior no se solventa en las relaciones de subordinación, antes bien parece complejizarse, pues (además de que igualmente existe una muy notable heterogeneidad en las asociaciones conceptuales que realizan los TrAm), 
como si se tratara de un juego de "muñecas rusas" o "cajas chinas", el entendimiento de un concepto presupone el de otro y, así sucesivamente; la comprensión de la libre valoración se hace descansar en la asimilación de la sana crítica, la que a su vez depende de la inteligibilidad -y más aún, de la combinación heterogénea para tributar un resultado homogéneo- de las reglas de la lógica, las ME, etcétera.

En las tesis no se dice cómo se efectúan esos ejercicios de subsunción ni tampoco cómo es que convergen, cual si se tratara de piezas de lego, para efectuar la valoración probatoria de manera unitaria; ni siquiera en los casos en que las tesis definen qué debe entenderse por ME, sana crítica, reglas de la lógica, etcétera.

Aun cuando en unas tesis el concepto clave para la valoración probatoria es la sana crítica, en otro la libre valoración o, ninguno, tales distinciones terminan por ser indiferentes: no existe claridad para saber cómo se articulan entre sí las diversas posibilidades de operaciones intelectuales para valorar las pruebas, cómo se discriminan, cómo convergen o se excluyen, ya sea que conceptualmente se encuentren en interacción horizontal o lineal, sin que ello se modifique porque en las tesis se defina o no qué debe entenderse por $\mathrm{ME}$ o algún otro de esos conceptos.

c. Un lugar común de argumentación, ${ }^{66}$ pues parece que el punto recurrente de los tratamientos jurisprudenciales que involucran las ME es una construcción argumentativa que conlleva una especie de apelación a la autoevidencia: un juego retórico de espejos con la legislación o con la obviedad de la práctica judicial (lo que da a entender que los jueces ya saben cómo hacerlo). ${ }^{67}$

66 Siguiendo a Aristóteles, los tópicos en la argumentación se refieren a lo que parece bien "ya para todos los hombres, ya para la mayor parte, ya para los sabios; y entre estos últimos, ya para todos, ya para los más de ellos, ya para los más ilustrados; interrogación que por otra parte no es paradójica; porque puede admitirse lo que parece verdadero a los sabios, con tal que no sea contrario a las opiniones generalmente recibidas" (ARISTóteles, Tratados de Lógica (Organon), Tópicos I, México, Porrúa, 2001, p. 316). En ese tenor: "al ser usados de manera reiterativa en los procesos argumentativos, no de naturaleza apodíctica o demostrativa sino a través de un proceso dialéctico, se convierten en tópicos" (José Julián SuÁREz RoldÁn, "El argumento de los principios en la teoria contemporánea del derecho: un alegato antipositivista", en Civilizar. Ciencias sociales y Humanas 22 (2012) p. 63. Para una visión más profunda sobre tópica y su relación con la argumentación y la retórica, véase: Alejandro GuZmán BRITo, "Dialéctica y retórica en la tópica de Cicerón”, en Revista de Estudios Histórico-Jurídicos 32, (2010); Francisco PuY, "Tópica jurídica. Un ensayo de distinción”, en Ars Iuris 31 (2004); Tópica jurídica. Tópica de expresiones, México, Porrúa, 2006; Patricio Martínez, "Sobre la influencia de Tópica y Jurisprudencia de Viehweg en el método de interpretación constitucional de Hesse", en Derecho y Justicia 4 (2014); Arturo Berumen, "Ponderación de principios y tópica jurídica”, en Boletín Mexicano de Derecho Comparado, 143 (2015); Joaquín Rodríguez Lugo Baguero, Argumentación jurídica e interpretación desde la Tópica Jurídica Podiana, México, Porrúa, 2010; Manuel Atienza, Derecho y argumentación, Santa Fe de Bogotá, Universidad Externado de Colombia, 1997; Las razones del derecho, México, UNAM, 2005; Ramón Beltrán, "La tópica jurídica y su vinculación argumentativa con el precedente y la jurisprudencia”, en Revista de derecho de la Pontificia Universidad Católica de Valparaíso 39 (2012); Pablo Sanz Bayón, "Sobre la tópica jurídica en Viehweg”, en Revista Telemática de Filosofia del Derecho, 16 (2013).

67 "La retórica parte para sus silogismos, no de principios evidentes, sino de aquello respecto de lo que existe alguna otra forma de convencimiento, de endoxa, y mediante la argumentación se hace 


\section{CONCLUSIONES}

De esta manera, las dos clasificaciones sobre las referencias de las ME en las tesis jurisprudenciales a las cuales se ha hecho referencia permiten advertir que, ante ese estado de indeterminación, no solo pudiera ser artificial la distinción entre la dimensión justificativa y epistemológica recién introducida -puesto que envuelve una circularidad: no se sabe dónde empieza una y acaba otra, cuál fundamenta a cuál, ambas lo hacen y ninguna lo hace-, sino que se plantea una cuestión más inquietante que la perplejidad e insuficiencia de clasificaciones analíticas, puesto que conlleva una paradoja de mayor calado y de notables implicaciones operativas: parece que las tesis de jurisprudencia se valen de un lugar común para llegar a un lugar común.

De esta manera, el proceso intelectivo del juzgador (no obstante las referencias explícitas a él en las tesis de jurisprudencia) sigue en la penumbra y, de ahí, que los criterios que refieren las tesis (que indican, con efectos disciplinarios para todos los jueces, la forma en que deben decidir cada caso concreto de la misma especie) se asemejan más a un ejercicio argumentativo de autoridad, como si los criterios dijeran: operador jurídico, mientras que puedas engarzar tus conclusiones probatorias a alguno de estos usos del lenguaje, a alguna de estas categorias conceptuales, estarás del lado de la decisión correcta, aunque no puedas explicar cómo es que tomaste esa decisión para el contexto probatorio que te planteaba la litis según las ME (o las reglas de la lógica o la sana crítica, etcétera), ni en qué sustentaste que, en efecto, el criterio comprendía la decisión concreta tomada en la sentencia; ello no será necesario porque la jurisprudencia te respalda.

Esto es de especial relevancia porque, de manera paradójica, las tesis apelan constantemente a que el juzgador debe tomar en cuenta las particularidades del caso y correlacionar las pruebas en su conjunto: sobre cómo toma en cuenta esas particularidades, cómo las correlaciona, las tesis nos dicen mucho al respecto.

Así, es también inocuo que las tesis refieran, de manera igualmente constante, que las $\mathrm{ME}$ y las otras categorias de incidencia probatoria sirvan para tomar decisiones razonables, lo que anclaría el fallo a un componente prudencial, pues en tanto que esa referencia está igualmente desarticulada de las indicaciones sobre cómo es que el juzgador debe navegar para llegar a ese buen puerto, debe tomarse como otro lugar común, lo cual tal vez obedeceria, al menos en parte, a que en las tesis solo se enuncia el supuesto (abstraido de su casuística) que motiva la generación de un criterio igualmente abstracto, sin que sea cognoscible el proceso intermedio que conecta ambos. Como el imput y el output, ubicados en los extremos de la caja negra, como si estuviera en la lógica de la teoria de sistemas. Más aún, la jurisprudencia operaría aquí en la lógica de la "cajanegrización", ${ }^{68}$ como

ver al auditorio que aquello de lo que se quiere convencer se sigue de aquello sobre lo que ya está convencido" (GARCía Amado, Teorías de la tópica jurídica, op. cit., p. 59).

68 Término que alude a las interacciones sociales con dispositivos tecnológicos en los que se obvia la complejidad de los procesos que los hacen posibles, que quedan ocultos dentro de su dispositivo 
un catálogo de opciones que se entrega al juzgador para que elija la que más se ajuste a sus necesidades.

De tal manera, tras el análisis del corpus jurisprudencial de trabajo es dable afirmar que las tesis, antes que responder a un baremo de reglas o de principios funcionan, más bien, como tópicos: si el título y la redacción de la tesis guarda relación con el problema jurídico que el juez tiene frente a sí, la tesis será pertinente; si es o no aplicable, eso dependerá del caso concreto. Sin embargo, a partir de esas mismas tesis no se sabe "de qué depende que en efecto dependa del caso": qué se toma en cuenta y cómo. Así, la referencia a las particularidades son otro gran lugar común que lleva a plantearnos: cuando la jurisprudencia mexicana interpreta las ME y conceptos conexos de incidencia probatoria, ¿qué es lo que está interpretando? ¿Qué pretenden los TrAm?

A lo cual podemos intentar, a modo de respuesta provisional que dé cierre a estas reflexiones, que las tesis nos dan criterios de un saber intelectual y de una aplicabilidad relegada: son más propias de unajurisprudencia de razón intelectual antes que de una jurisprudencia de razón práctica; entre más criterios conozca el operador más sabrá de los problemas del derecho y de sus soluciones, pero no necesariamente sabrá más acerca de cómo resolverlos.

Las ME sirven de botón de muestra representativo. Las tesis nos dan un saber conceptual, más o menos claro, de una aplicabilidad poco clara, lo que va más allá de la polisemia del concepto; que las ME sirvan para decidir el valor de una prueba, para colmar lagunas, etcétera, es algo fácilmente identificable y, al final de cuentas, ello es propio de tantos otros términos equivocos en el derecho. No obstante, la principal cuestión aquí es que las ME asoman la gran paradoja de tesis de jurisprudencia pensadas para resolver casos futuros sin guía de cómo andar el camino para hacerlo.

\section{BIBLIOGRAFÍA}

ADAME, Jorge, "El derecho como jurisprudencia”, en Ars Iuris 12 (1994), pp. 1038, en https://revistas-colaboracion.juridicas.unam.mx/index.php/ars-iuris/ article/view/2105

AREnAL, Vicente Roberto, La técnica en el juicio de Amparo, México, Flores Editor, 2016.

interior (su caja negra), con lo cual los usuarios se desentienden de su funcionamiento, que no tendría mayor importancia en tanto que la interacción con ellos está limitada a su aspecto más utilitario y así, estos dispositivos, en tanto "estados de cosas se convierten en hecho incuestionable y luego en rutina [...] Esta es una expresión tomada de la sociología de la ciencia que se refiere al modo en que el trabajo científico y técnico aparece visible como consecuencia de su propio éxito. Cuando una máquina funciona eficazmente, cuando se deja sentado un hecho cualquiera, basta con fijarse en los datos de entrada y los de salida, es decir, no hace falta fijarse en la complejidad interna del aparato o del hecho. Por tanto, y paradójicamente, cuanto más se agrandan y difunden los sectores de la ciencia y de la tecnologia que alcanzan el éxito, tanto más opacos y oscuros se vuelven" (Bruno Latour, La esperanza de Pandora. Ensayos sobre la realidad de los estudios de la ciencia, Barcelona, Gedisa, 1999, pp. 190 y 362). 
Aristóteles, Tratados de Lógica (Organon), Tópicos I, México, Porrúa, 2001.

Atienza, Manuel, Derecho y argumentación, Santa Fe de Bogotá, Universidad Externado de Colombia, 1997.

Atienza, Manuel, Las razones del derecho, México, UNAM, 2005.

Baltazar Robles, Germán Eduardo, Derechos humanos, derechos fundamentales, juicio de Amparo y reparación integral: derechos humanos reconocidos en la Constitución Mexicana y su justiciabilidad mediante el juicio de Amparo, México, Complejo Educativo de Desarrollo Integral, 2015.

Beltrán CAlfuRRAPA, Ramón, "La tópica jurídica y su vinculación argumentativa con el precedente y la jurisprudencia”, en Revista de derecho de la Pontificia Universidad Católica de Valparaiso 39 (2012), pp. 588-606. DOI: http://dx.doi. org/10.4067/S0718-68512012000200021

Berumen Campos, Arturo, "Ponderación de principios y tópica jurídica", en Boletín mexicano de derecho comparado 143 (2015), pp. 531-546. DOI: http://dx.doi. org/10.22201/iij.24484873e.2015.143.4939

Coloma, Rodrigo y Claudio San Juan, "Lógica, ciencia y experiencia en la valoración de la prueba”, en Revista Chilena de Derecho 41 (2014), pp. 673-703. DOI: http://dx.doi.org/10.4067/S0718-34372014000200011

Fernandez, Vicente y Nitza Samaniego, "El juicio de amparo: historia y futuro de la protección constitucional en México", en Revista IUS 27 (2011), pp. 173-200, en http://www.scielo.org.mx/scielo.php?script=sci_arttext\&pid $=$ S1870-21472011000100009

Ferrer Mac-Gregor, Eduardo, El juicio de Amparo y el sistema procesal penal acusatorio, México, Segob-Setec, 2012.

Ferrer Mac-Gregor, Eduardo, El nuevo juicio de Amparo: guía de la reforma constitucional y la nueva ley de Amparo, México, Porrúa, 2016.

Ferrer Mac-Gregor, Eduardo y Fernando Silva, "El caso Radilla y su impacto en el orden jurídico nacional”, en Jorge CARPIzo y César Astudillo (coords.), Constitucionalismo: dos siglos de su nacimiento en América Latina, México, UNAMIIJ, 2013, pp. 185-235.

Fix ZAmudio, Héctor, Las reformas en derechos humanos, procesos colectivos y Amparo como nuevo paradigma constitucional, México, UNAM-IIJ, 2012.

García Amado, Juan Antonio, Teorías de la tópica juridica, Perú, Palestra, 2018.

Gaxiola, Jorge F., "El juicio de amparo", en Mariano Otero, visionario de la República. A 200 años de su nacimiento, vol. A, México, Suprema Corte de Justicia de la Nación-El Colegio de Jalisco, pp. 75-208.

Gil, Raymundo, El Amparo y los derechos humanos, México, Ubijus, 2017.

Guzmán BRITo, Alejandro, "Dialéctica y retórica en la tópica de Cicerón", en Revista de Estudios Histórico-Jurídicos 32 (2010), pp. 161-195. DOI: http://dx.doi. org/10.4067/S0716-54552010000100007 
Jarguín Orozco, Wendy Mercedes, La naturaleza subjetiva del Amparo: análisis histórico-comparado y de derecho español, México, Porrúa, 2016.

LATour, Bruno, La esperanza de Pandora. Ensayos sobre la realidad de los estudios de la ciencia, Barcelona, Gedisa, 1999.

Lembo Rosales, Francisco A., El nuevo régimen constitucional del juicio de Amparo y los derechos humanos: a la luz de la reforma constitucional del 2011 y con base en la nueva Ley de Amparo, México, Flores Editor, 2016.

Martinez Benavides, Patricio, "Sobre la influencia de Tópica y Jurisprudencia de Viehweg en el método de interpretación constitucional de Hesse”, en Derecho y Justicia 4 (2014), pp. 117-138, en http://ediciones.ucsh.cl/ojs/index.php/ derechoyjusticia/article/view/916

Monargue Ureña, Rodolfo, La suspensión en el juicio de Amparo: planteamiento esquemático, México, Porrúa, 2016.

Puy Muñoz, Francisco, "Tópica jurídica. Un ensayo de distinción”, en Ars Iuris 31 (2004), 271-293, en https://revistas-colaboracion.juridicas.unam.mx/index. php/ars-iuris/article/view/2512/

Puy Muñoz, Francisco, Tópica jurídica. Tópica de expresiones, México, Porrúa, 2006.

Rodríguez Lugo Baguero, Joaquín, Argumentación jurídica e interpretación desde la Tópica Jurídica Podiana, México, Porrúa, 2010.

SANDOval, Emiliano, "La libre valoración de la prueba en los juicios orales: su significado actual”, en Letras Jurídicas 13 (2011), pp. 1-23, en https://www. academia.edu/6347065/LA_LIBRE_VALORACI\%C3\%93N_DE_LA_PRUEBA_ EN_LOS_JUICIOS_ORALES_SU_SIGNIFICADO_ACTUAL_SELF-ASSESSMENT_ OF_THE_EVIDENCE_IN_THE_TRIAL_THE_ACTUAL_MEANING

Sanz, Pablo, "Sobre la tópica jurídica en Viehweg", Revista Telemática de Filosofía del Derecho 16 (2013), pp. 83-108, en https://ssrn.com/abstract=2252866

Silva Ramírez, Luciano, El control de la constitucionalidad y el juicio de Amparo en México, México, Porrúa, 2017.

SosA, Alejandro, La jurisprudencia en la nueva Ley de Amparo, México, Porrúa, 2015.

SuÁREz RoldÁn, José Julián, "El argumento de los principios en la teoria contemporánea del derecho: un alegato antipositivista, Civilizar. Ciencias sociales y Humanas 22 (2012), pp. 57-75. DOI: https://doi.org/10.22518/16578953.91

TARUfFo, Michele, "Precedente y jurisprudencia”, en Precedente. Revista Jurídica (2007), pp. 85-99. DOI: https://doi.org/10.18046/prec.v0.1434

Trocolli Lugo, José Vicente, Evolución del juicio de Amparo como medio de control constitucional, México, Porrúa, 2013.

VIEHWEG, Theodor, Tópica yjurisprudencia., Madrid, Taurus, trad. Luis Díez-Picazo Ponce de León, 1964.

VIGo, Rodolfo Luis, "Razonamiento justificatorio judicial", en Doxa 21 (1998), pp. 483-499. DOI: https://doi.org/10.14198/DOXA1998.21.2.33 